readily and it has been confirmed that where abnormalities existed opticians did not fail to detect them. ${ }^{1}$ It is, however, an assumption to conclude that an optician is therefore better able to examine a retina. It is true that they are trained in fundoscopy, but any abnormality that might be found beyond their experience of the normal must be referred to the general practitioner, who in turn is likely to refer the patient to the hospital eye service. It is our experience that most of these referrals are for lesions which are of no clinical importance and it is exceptionally rare for diabetes to be detected by the observation of retinopathy in a person who is otherwise not known to be suffering from the disease.

It is perhaps regrettable that many diabetic patients receive their only eye examination by the optician, even though most will also be under the care of the general practitioner or a physician. General practitioners do express anxiety about their ability to detect retinopathy; however, it is not difficult for a doctor to acquire the necessary techniques and apply them routinely. As general practitioners become increasingly aware of the need to detect diabetic retinopathy many are improving their own fundoscopy techniques, and many large practices are ensuring that at least one partner obtains and continues to enjoy sufficient experience in the examination of the retina so that fundoscopy is no more of a worry than measuring blood pressure or listening to changes in heart sounds. It would also be helpful if physicians caring for diabetics routinely dilate their pupils and examine their fundi. Very many do not.

Ophthalmic opticians provide a valuable service in testing for glasses, and they may play a part in routine testing of intraocular pressure. However, mixing the commercial aspect of selling glasses with the primary care of patients has led many ophthalmologists to express concern that the screening of diabetics may expand into the market place.

Dr Yudkin presents a compelling case for the screening of diabetic retinas, but let this be done by doctors and not by ophthalmic opticians. The discussion which has been engendered by the proposal to charge people for an eye test by opticians should serve to highlight the problem of screening of diabetics and to encourage doctors to take upon themselves this responsibility.

JOHN D SCOTT

Director,

Regional Retina Service

East Anglia

Declan Flanagan

Addenbrooke's Hospital,

Cambridge CB2 2QQ

1 Burns-Cox CJ, Dean Hart JC. Screening of diabetics for retinopathy by ophthalmic opticians. Br Med f 1985;290: $1052-4$.

\section{Treatment of Paget's disease of bone}

SIR,-Like Dr H I J Harinck and others (21 November, p 1301), ${ }^{1}$ we have found aminohydroxypropylidene bisphosphonate to be highly effective and safe in the treatment of Paget's disease of bone. ${ }^{2}$ We believe, however, that the regimen of intravenous aminohydroxypropylidene bisphosphonate which they gave to 32 patients, consisting of 10 consecutive daily infusions of $20 \mathrm{mg}$ aminohydroxypropylidene bisphosphonate intravenously with the response monitored closely by 24 hour urine hydroxyproline estimation, is expensive and impracticable for routine use. Most affected patients are elderly, and daily treatment-certainly with 24 hour urine collections-requires the expense and disruption of inpatient admission.

We have developed an equally successful treatment strategy which depends on a course of weekly or fortnightly infusions of aminohydroxypropylidene bisphosphonate intravenously in $0.9 \%$ saline, and we have now treated 133 patients in this way. Our current regimen is to start with a single infusion of $30 \mathrm{mg}$ in $250 \mathrm{ml}$ saline over two hours, followed in one week by $60 \mathrm{mg}$ in $500 \mathrm{ml}$ saline over four hours; the latter is repeated at 14 day intervals, twice for disease of moderate extent and activity (total dose of $210 \mathrm{mg}$ ) and five times for more extensive disease (total dose of $390 \mathrm{mg}$ ). If it is considered necessary then estimation of a fasting morning hydroxyproline:creatinine ratio is perfectly adequate, but for week to week monitoring of response alkaline phosphatase estimations are generally sufficient. We do not agree that "short intravenous courses must be followed by oral aminohydroxypropylidene bisphosphonate" in patients with high disease activity. Such patients simply require longer and higher doses intravenously, and for resistant cases of "megaPaget's" we have eventually given as much as $120 \mathrm{mg}$ intravenously weekly as an infusion over four hours for 12 weeks without adverse effects, and usually with good response.

Dr Harinck and his colleagues also state that about $1 \%$ of oral aminohydroxypropylidene bisphosphonate is absorbed, but this calculation is based on the most tenuous of indirect evidence. Until much more is known of the absorption and pharmacodynamics of aminohydroxypropylidene bisphosphonate it seems unlikely that a satisfactory pharmaceutical preparation of oral aminohydroxypropylidene bisphosphonate will become available, especially for treatment of a non-malignant disease that in most cases can be so effectively controlled by outpatient administration of a short course of intravenous infusions.

Finally, concerning the mechanism of action of aminohydroxypropylidene bisphosphonate in this condition, we would urge caution in extrapolating from the authors' excellent animal experiments on normal rat and mouse osteoclasts and precursors to the highly abnormal osteoclasts of Paget's disease a condition which as far as we know is confined to humans.

DAVID C ANDERSON JUDY C CANTRILI

Department of Medicine (Endocrinology),

Hope Hospital, Salford M6 8HD

1 Harinck HIJ, Bijvoet OLM, Blanksma HJ, DallinghausNienhuys PJ. Efficacious management with amino-bisphosphonate (APD) in Paget's disease of bone Clinical Orthopaedics and Related Research 1987;217:79-98.

2 Cantrill JA, Buckler HM, Anderson DC. Low dose intravenou 3-amino-1-hydroxypropylidene-1,1-bisphosphonate (APD) for the treatment of Paget's disease of bone. Ann Rheum Dis 1986;45:1012-8.

\section{Caffeine and health}

SIR,-Dr C H Ashton discussed possible relations between caffeine and health, particularly menta health (21 November, p 1293). We have investigated associations between coffee consumption and mental problems in a general population with high coffee consumption.

During the second Troms $\varnothing$ heart study $(1979-80)$ nearly 143000 men and women answered several questions about, among other topics, coffee consumption and symptoms of mental problems (depression, difficulty in coping with the problems of daily life, insomnia). The response rate to the self administered questionnaire was $88 \% .^{1} \mathrm{We}$ compared the prevalence of these reported mental problems in subjects with a high coffee consumption ( $>8$ cups per day) with the prevalence in subjects with lower consumption. The table gives the age adjusted figures.

We found no association between high coffee consumption and mental problems in men, whereas in women consistent and statistically significan $(p \leqslant 0.001$ for depression and problems with coping) associations were observed (table). The reason for the lack of effect in men may be that the highest consumption category considered in this study ( $>8$ cups of coffee per day) does not represent a sufficiently heavy consumption in men; $16 \%$ of the men in this population drank $>8$ cups of coffee daily whereas the corresponding figure among women was $9 \cdot 6 \%$.

Coffee consumption and mental problems. Prevalence (\%) of self reported mental problems according to coffee consumption (Tromsø 1979-80)

\begin{tabular}{|c|c|c|c|c|c|c|}
\hline \multirow{3}{*}{$\begin{array}{l}\text { Coffee } \\
\text { consumption } \\
\text { (cups/day) }\end{array}$} & \multicolumn{6}{|c|}{$\%$ Reporting symptoms of mental problems } \\
\hline & \multicolumn{2}{|c|}{ Depression } & \multicolumn{2}{|c|}{$\begin{array}{l}\text { Problems with } \\
\text { coping }\end{array}$} & \multicolumn{2}{|c|}{ Insomnia } \\
\hline & Men & Women & Men & Women & Men & Women \\
\hline $\begin{array}{l}>8 \\
\leqslant 8\end{array}$ & $\begin{array}{l}9 \\
9\end{array}$ & $\begin{array}{l}16 \\
12\end{array}$ & $\begin{array}{l}7 \\
6\end{array}$ & 11 & $\begin{array}{l}5 \\
5\end{array}$ & $\begin{array}{r}10 \\
8\end{array}$ \\
\hline
\end{tabular}

As in all cross sectional studies, we cannot conclude whether coffee consumption is the cause or the effect of the self reported mental problems. When the associations found in women are adjusted for cigarette smoking they tend to disappear. Thus, in this population with relatively high consumption, coffee consumption is probably part of a lifestyle associated with mental problems.

Unfortunately, we do not have information about other symptoms of mental discomfort. Thus, we cannot exclude relations between coffee drinking and, for example, anxiety. Furthermore it cannot be ruled out that subjects who experience effects of coffee drinking on psychological health reduce their coffee consumption, thereby making it less likely that a relation will be observed. Finally, we cannot exclude the possibility that coffee consumption influences the symptoms of mental ill health in subjects with very heavy coffee consumption. Such effects may, however, be difficult to show in a cross sectional study in a general population because of problems with confounding and because few individuals, even in Norway, where coffee consumption is high, have a very heavy chronic use.

BJARNE K JACOBSEN VIDJE HANSEN

Institute of Community Medicine,

University of Tromsø,

Tromsø, Norway

1 Thelle DS, Arnesen E, Førde OH. The Tromsø heart study. Does coffee raise serum cholesterol? N Engl f Med 1983;308: 1454-7.

\section{Clinical experimentation in obstetrics}

SIR,-Do those who, like Professor R J Lilford, worship the icon of the double blind random placebo matched control trial (21 November, p 1298) ever stop to think about not only the pedestrian rate but also the mediocre quality of the research into which they have poured resources? None of the major advances in obstetric knowledge or practice have come from double blind controlled trials. If a question is of real importance, or the answer has major impact, such a trial is not needed for its solution and controls are merely to assess "background noise." 
The housemen who hold the sealed envelopes up to the light to select appropriate management for the patient, or the patient who rapidly appreciates any meaningful differences in the active preparation, are not blind in these trials. Only the designer is really blind-to the mangled English of the word "randomised" and to the fact that allocation at random is less efficient statistically than "alternate case" design.

If very large numbers of cases are required for a controlled study then either the question asked at the start is inappropriate or the answer is not worth having at the end.

The importance of the difference being tested is inversely related to its ethical validity. Tunnel vision with respect to ethics is illustrated by the patient information pamphlet on the Medical Research Council's chorion villus biopsy versus amniocentesis trial. To describe a 19 to 20 week legal abortion for an abnormal fetus as "a bit more difficult" than a similar procedure at 12 weeks is more than "economical with the truth." The patients were not gullible and there were no recruits to the "willing to be randomised" group. It is regrettable that the results of the trial will now be based on a biased selection of women of too low intelligence to understand the women's magazines.

There is light on the horizon. The recent introduction of Cox (staged logistic) multiple regression analysis ${ }^{1}$ and path analysis ${ }^{2}$ into obstetric research has provided powerful tools which can be used to obtain important results from traditional retrospective studies or open clinical trials. These analyses isolate meaningful and causa associations with no vital necessity for controls or putting patients into artificial slots which may not be to their advantage. Perhaps it will not be too long before their application will send the banner of "double blind controlled trials for obstetric research" back to the home of lost causes.

DENIS F HAWKINS

Royal Postgraduate Medical School,

Institute of Obstetrics and Gynaecology,

Hammersmith Hospital

London W12 OHS

1 Nelson KB, Ellenberg JH. Antecedents of cerebral palsy. Multivariate analysis of risk. $N$ Engl f Med 1986;315:81-6.

2 Rogers MS, Chang AMZ. Perinatal asphyxia: the use of path analysis in its explanation. $\mathcal{F}$ Obstet Gynaecol 1987;8:29-35.

\section{Leucocyte sodium pump activity after meals or insulin}

SIR,-Dr Leung $\mathrm{L} \mathrm{Ng}$ and colleagues (28 November, $p$ 1369) suggest that the total activity of leucocyte sodium pumps is reflected by the ouabain sensitive sodium efflux rate and that a defect in postprandial activation of the pump in obese people may ultimately lead to positive energy balance.

Their values of ouabain sensitive sodium efflux rate are derived from the product of their measurements of ouabain sensitive sodium efflux rate constant $\left(\mathrm{k}_{0}\right.$, and white cell sodium concentration $\left(\mathrm{Na}_{w_{B C}}\right)$. For this calculation to be valid $\mathrm{Na}_{\mathrm{WBC}_{B C}}$ and $\mathrm{k}_{0}$ should be measured under similar conditions. If this is not possible intracellular sodium content and flux should be shown to be the same in the differing conditions. In their experiments $\mathrm{Na}_{\text {wBC }}$ was measured in cells which had been incubated for $\mathbf{3 0}$ minutes to allow recovery from the isolation procedure, but $k_{0}$ was measured over 20 minutes immediately after two centrifugations and a wash in tissue culture fluid.

In our work with leucocytes we have been impressed by the extreme sensitivity of the cells to handling and the isolation procedure. In particular, in leucocytes from five normal subjects we measured $\mathrm{Na}_{\mathrm{wBC}}$ serially from the time of isolation and found in every case that the sodium content in the first few minutes after isolation was about twice as high as the final, stable value reached after 20 to 45 minutes. From our experience we would expect that the washing procedure used to remove ${ }^{22} \mathrm{Na}$ would raise $\mathrm{Na}_{W B C}$, and when we subjected cells which had been incubating for 60 minutes to a procedure like that used by $\mathrm{Dr} \mathrm{Ng}$ and colleagues we found a $30 \%$ increase in $\mathrm{NawBC}$. Although their method has been widely used since it was described by Hilton and Patrick in $1973,{ }^{1}$ we are unaware of published evidence that either sodium content or sodium efflux rate is constant under the conditions used to measure $\mathrm{k}_{0}$. We therefore believe that sodium efflux rate should not be calculated in this way. The extremely high standard deviations for $\mathrm{Na}_{W B C}$ in their groups add to our concern about the validity of the calculated ouabain sensitive sodium efflux rates on which their conclusions rely.

JoHn MAIN TH THOMAS

Freeman Hospital,

Newcastle upon Tyne NE7 7DN

1 Hilton PJ, Patrick J. Sodium and potassium flux rates in human leucocytes in an artificial extracellular fluid. Clin Sci 1973;44: 439-45.

\section{Child abuse and osteogenesis imperfecta}

SIR,-The claim by Drs Colin R Paterson and Susan J McAllion to have seen 13 cases of type IVA osteogenesis imperfecta misdiagnosed as child abuse (12 December, p 1561) would carry more conviction if they had published them in detail in a form that would enable others to make an independent judgment of the correctness of their opinion. In a recent case, with which I was concerned, Dr Paterson failed to convince a court that an abused child had osteogenesis imperfecta. Dr Paterson needs to explain how he diagnoses osteogenesis imperfecta without a family history, no radiological features, and no repeated fractures. In this case he based it on absence of bruises, a single fracture in a cousin, and joint hyperflexibility in both parents-a curious finding in an autosomal dominant condition.

Dr Paterson seems to be in two minds in ascribing "unexplained" fractures in young babies to either osteogenesis imperfecta or copper deficiency. In the recent case of Lees, ${ }^{1}$ Dr Paterson first gave evidence at the trial for the defence diagnosing osteogenesis imperfecta. Later after further research he changed his diagnosis to copper deficiency. On appeal, when the accused sought a new trial, the Lord Chief Justice expressed regret that Dr Paterson had not done his research before giving evidence initially. Lord Lane said that no doubt the result of the trial was a disappointment to Dr Paterson and he was moved thereby to carry out extensive research into the literature of copper deficiency. The court stated it was unimpressed by much of what Dr Paterson had said and rejected his evidence as a basis for a retrial.

This rejection was echoed in a recent wardship case, where the judge declined to accept $\mathrm{Dr}$ Paterson's evidence. On that occasion the court found that Dr Paterson was mistaken in diagnosing anaemia, having relied on erroneous American tables for haemoglobin concentrations, and rejected Dr Paterson's evidence that he had measured the anterior fontanelle of the child at $4.8 \mathrm{~cm}$ across. Dr Paterson's approach seems to be to find evidence of collagen defect such as hyperextensibility of the joints in a parent or relative on the basis of clinically controversial procedures and use this as a peg on which to hang the diagnosis of either copper deficiency or osteogenesis imperfecta. Such procedures are not entirely satisfactory. It seems that Dr Paterson now seems to believe that of his two suits osteogenesis imperfecta type IVa is probably the stronger. On the evidence he has produced so far it is not strong enough.

L S TAITZ

Department of Paediatrics,

Children's Hospital,

Sheffield

Regina $v$ Lees and Lees: Court of Criminal Appeal. February 1987.

SIR,-While sharing the anxieties of Drs Colin $R$ Paterson and Susan J McAllion (12 December, p 1561) that children with osteogenesis imperfecta may be misdiagnosed as victims of non-accidental injury, we are equally concerned that children who are abused may be incorrectly diagnosed as suffering from osteogenesis imperfecta, cutis laxa, copper deficiency, or other metabolic bone diseases which have been used as "defence" submissions in care or criminal proceedings.

In particular, we feel that adequate substantiation of the diagnosis of osteogenesis imperfecta in patients with type IVA disease, who had the highest level of suspicion of non-accidental injury, has not been made. In a recent paper by $\mathrm{Dr}$ Paterson of the cohort of 78 patients with type IVA osteogenesis imperfecta the authors examined radiographs of only 17 patients, among whom only 12 sets of skull radiographs were available. The observed incidence of skull fractures of $28 \%$ in mild osteogenesis imperfecta is difficult to accept. Similarly, patient delineation by questionnaire is subject to vagaries of recall and open to errors of fact.

Until definitive diagnosis, perhaps by better biochemical analysis of collagen or by gene analysis, is available, there must be continuing doubt about the accuracy of the diagnosis of some cases of type IVA disease as described by Dr Paterson and his colleagues.

Alder Hey Children's Hospital,

Helen Carty Liverpool L12 2AP

The Hospital for Sick Children,

DONALD G SHaW

Great Ormond Street,

London WC1

1 Paterson CR, McAllion SJ, Shaw JW. Clinical and radiological features of osteogenesis imperfecta type IVA. Acta Paediat Scand 1987;76:548-52.

\section{Free radicals and Dupuytren's contracture}

SIR,-The observation of Dr G A C Murrel and others (28 November, p 1373) that xanthine oxidase activity was present in the palmar fascia of patients with Dupuytren's contracture might also be extended to the tendon sheath problems seen with inflammatory synovitis.

The tendon sheath is lined with a synovial intima. We have found that the synovial lining of both normal and rheumatoid joints also contains xanthine oxidase activity ${ }^{1}$ and have therefore suggested that the inflamed joint may be the target of damage by free radicals promoted by this enzyme. ${ }^{23}$ We have provided direct evidence that the mobile inflamed joint is subject to hypoxic reperfusion injury. ${ }^{4} \mathrm{~A}$ similar sequence of events might explain the pathological changes observed in rheumatoid tendons as the inflamed synovial lining is likely to become ischaemic on movement, allowing the build up of hypoxanthine and xanthine. The ischaemic process would allow the conversion of normal xanthine dehydrogenase to an oxidase 